ORIGINAL ARTICLE

\title{
A follow up study of vibration induced white finger in compensation claimants
}

\author{
M Bovenzi, A Della Vedova, C Negro
}

Occup Environ Med 2005;62:237-242. doi: 10.1136/oem.2004.014704

See end of article for authors' affiliations

.....................

Correspondence to: Prof. M Bovenzi, Unità Clinica Operativa di Medicina del Lavoro, Dipartimento di Scienze di Medicina Pubblica, Università degli Studi di Trieste, Centro Tumori, Via della Pietà, 19, 1-34129

Trieste, Italy; bovenzi@ units.it

Accepted 1 December 2004

...................
Aims: To follow up vibration induced white finger (VWF) in a selected group of 73 vibration exposed workers who claimed unsuccessfully for WWF compensation at a first examination.

Methods: The VWF claimants were sent to our unit by the National Insurance Institute. The basic compensatory criteria included a positive history of WWF and abnormal cold response of the digital arteries. Following the first unsuccessful examination, over a mean time period of 4.1 (range 1-11) years the National Insurance Institute requested a second examination for all 73 claimants and a third examination for 29. During the follow up period, all subjects continued to work with vibratory tools.

Results: There were 14 new cases who reported white finger during the follow up period. In the new VWF cases, finger blanching attacks became visible after about 3.5 years since the first examination. All incident cases of anamnestic WWF showed an abnormal cold response in the digital arteries and obtained compensation according to the basic compensatory criteria. In the entire sample of WWF claimants, there was a discrepancy between positive history of WWF symptoms at medical interview (55\%) and abnormal cold provocation outcomes (19\%). Digital arterial hyperresponsiveness to cold was associated with both WWF symptoms and the duration of vibration exposure since the first examination. Over the follow up period, a significant increase in the vasoconstrictor response to cold was observed in the vibration exposed workers with no symptoms of finger whiteness. Abnormal cold response was not associated with either age or smoking habit.

Conclusions: Cold test measuring finger systolic blood pressure may be considered a useful laboratory method to confirm objectively WWF symptoms and to disclose abnormal cold induced vasoconstrictor response in vibration exposed workers with a negative history of WWF. Medical interview outcomes should be interpreted with caution in medicolegal situations involving VWF claimants.
$\mathrm{T}$ he prognosis of vibration induced white finger (VWF) is still uncertain. Studies have reported that VWF may improve, persist, or worsen in workers with current or previous exposure to hand transmitted vibration. It has been suggested that cessation or reduction of vibration exposure may be associated with some reversibility of VWF, but the rate of remission of vasospastic symptoms over time is not well known. ${ }^{1-4}$ On the other hand, there is clinical and epidemiological evidence that continued use of vibrating tools is associated with an unfavourable prognosis for VWF. ${ }^{5-7}$ Most of the longitudinal studies of the prognosis of VWF, however, are based on anamnestic findings. Only a few investigators have monitored the natural course of VWF by means of objective clinical tests, in addition to health history. ${ }^{18-10}$

The aim of this follow up study was to investigate the changes in vascular symptoms and the cold response of digital arteries in a selected group of claimants for VWF compensation.

\section{METHODS}

\section{Subjects and medical investigation}

From 1988 to 2002, 177 workers claiming for VWF compensation were sent to us by the National Insurance Institute for clinical and laboratory examinations. One hundred and four subjects were compensated on the basis of the compensatory criteria established in our country-that is, a positive history of VWF and abnormal vasoconstrictor response to cold provocation. The remaining 73 claimants did not obtain compensation at the first examination because of a negative medical history for VWF, positive history of VWF but negative cold test results, or incomplete administrative documentation.

Following the first unsuccessful examination, over a mean time period of 4.1 (range 1-11) years the National Insurance Institute requested a second examination for all 73 claimants and a third examination for 29 of them. During the follow up period, all subjects continued to work with vibratory tools.

At the first examination and at each follow up, workers underwent a medical interview, a complete physical examination, and a standardised cold test. Subjects were interviewed on their work history, state of health, and consumption of tobacco and alcohol. Cigarette smoking was expressed as pack-years ([cigarettes/day/20] $\times$ years smoked).

The anamnestic diagnosis of VWF was based on the following criteria: ${ }^{11}$ (1) positive history of cold provoked episodes of well demarcated blanching in one or more fingers; (2) first appearance of finger blanching after the start of occupational exposure to hand transmitted vibration and no other probable causes of Raynaud's phenomenon; and (3) experience of finger blanching attacks during the last two years. VWF symptoms were staged according to the Stockholm scale. ${ }^{12}$ In this study, however, VWF staging was based on the extent of finger blanching, since our clinical experience, as well as that of other researchers, showed that the verbal descriptors for the frequency of attacks used in the Stockholm scale ("occasional", "frequent") are potentially ambiguous and scarcely reliable. ${ }^{19}$ Thus, VWF was graded

Abbreviations: FSBP, finger systolic blood pressure; GEE, generalised estimating equations; VWF, vibration induced white finger 


\section{Main messages}

- In this follow up study, several new cases of VWF occurred over a short time period in currently active vibration exposed workers who claimed for VWF compensation.

- Medical interview outcomes should be interpreted with caution in medicolegal situations involving VWF claimants.

- A standardised cold test with measurement of finger systolic blood pressure was a useful diagnostic tool to confirm objectively VWF symptoms and to reveal exaggerated cold induced digital vasoconstriction in vibration exposed workers without episodes of finger whiteness.

- During follow up, deterioration of the cold response of digital arteries was associated with VWF symptoms and the duration of vibration exposure since the first examination.

- Abnormal cold response was not associated with either age or smoking habit.

according to the following modified Stockholm scale: stage $\mathrm{l}=$ blanching attacks affecting only the tips of one or more fingers; stage 2 =blanching attacks affecting distal and middle (rarely proximal) phalanges of one or more fingers; stage 3 = blanching attacks affecting all phalanges of most fingers.

An increase or a fall of finger whiteness in at least six phalanges was required to define, respectively, a deterioration or an improvement of the number of phalanges affected with whiteness over the follow up period.

\section{Cold test}

The cold test was performed with the subject in a supine position after a rest period of 20-30 minutes in a laboratory room with an ambient temperature of $21-23^{\circ} \mathrm{C}$. The cold test consisted of strain gauge plethysmographic measurement of finger systolic blood pressure (FSBP) during local cooling according to a standardised technique. ${ }^{13}$ A double inlet plastic cuff for both air filling and water perfusion was placed on the middle phalanx of the third left finger. In the subjects with symptoms of VWF, the most affected finger was cooled. The test finger was thermostated with water circulating at $30^{\circ} \mathrm{C}$ and $10^{\circ} \mathrm{C}$ by using a digit cooling system. Two air filled cuffs were applied, one to the proximal phalanx of the test finger (for ischaemia during cooling), and one to the middle phalanx of a reference finger of the same hand (usually the fourth finger). The cold test was performed by pressurising the air cuffs to a suprasystolic level $(210 \mathrm{~mm} \mathrm{Hg})$ and perfusing the water cuff with water, initially at $30^{\circ} \mathrm{C}$ and then at $10^{\circ} \mathrm{C}$. After five minutes of ischaemic cooling, FSBP was measured by a strain gauge in the distal phalanx of the test and reference finger. The results of the cold test were expressed as the change of systolic blood pressure in the test finger at $10^{\circ} \mathrm{C}\left(\mathrm{FSBP}_{\mathrm{t}, 10^{\circ}}\right)$ as a percentage of the pressure at $30^{\circ} \mathrm{C}\left(\mathrm{FSBP}_{\mathrm{t}, 30^{\circ}}\right)$, corrected for the change of pressure in the reference finger during the examination $\left(\mathrm{FSBP}_{\mathrm{ref}, 30^{\circ}-}\right.$

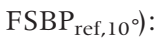

$$
\begin{aligned}
& \mathrm{FSBP}_{10^{\circ}}=\left(\mathrm{FSBP}_{\mathrm{t}, 10^{\circ}} \times 100\right) /\left(\mathrm{FSBP}_{\mathrm{t}, 30^{\circ}}-\left(\mathrm{FSBP}_{\mathrm{ref}, 30^{\circ}}-\right.\right. \\
& \left.\left.\operatorname{FSBP}_{\mathrm{ref}, 10^{\circ}}\right)\right)(\%)
\end{aligned}
$$

To avoid nicotine induced vasoconstrictive effects on the digital arteries, tobacco users were instructed to refrain from smoking on the morning of the test or for at least two hours

\section{Policy implications}

- VWF is included in the new schedule of occupational diseases (Annex I, item 505.02) recommended by the European Commission (2003/670/EC).

- If a worker is found to be affected with an identifiable disease or adverse health effect caused by mechanical vibration at work, the European Directive on physical agents (2002/44/EC) establishes that "the employer shall ... arrange continued health surveillance and provide for a review of the health status of any other worker who has been similarly exposed. In such case, the competent doctor or occupational health care professional or the competent authority may propose that exposed persons undergo a medical examination".

before attending the laboratory. Since medical procedures, subject's acclimatisation, and preparation for the cold test required about two hours, this extra time lag was considered sufficient to comply with the recommendation of International Standard ISO/DIS 14835-2 about avoiding smoking prior to testing. ${ }^{14}$ All subjects avoided working with vibratory tools for at least 12 hours prior to examination. ${ }^{14}$

The cold test at the various surveys was performed by the same method and apparatus (Digitmatic 2000, Medimatic A/S, Copenhagen, Denmark).

In a previous study of the cold response of digital arteries in 455 normal subjects, we found that $\mathrm{FSBP} \% 10^{\circ}$ averaged $94.8 \%$ (SD 11.8). ${ }^{15}$ For medicolegal purposes, in the present study the finding of $\mathrm{FSBP} \%_{10^{\circ}}<60 \%$ (mean $-3 \mathrm{SD}$ in normals) was considered an abnormal response of the digital arteries to cold provocation. The same criterion was applied to define an improvement or a deterioration of cold response over the follow up period-that is, an improvement if $\mathrm{FSBP} \% 10^{\circ}$ changed from a value lower to a value higher than $60 \%$, a deterioration if $\mathrm{FSBP} \% 10^{\circ}$ changed in the opposite direction.

\section{Statistical methods}

Data analysis was performed with the statistical software Stata version 8.2 (Stata Corporation, 2003) and StatXact version 4.0.1 (Cytel Software Corporation, 1992). Continuous variables were summarised using means or medians as measures of central tendency and standard deviations (SD), quartiles, or range as measures of dispersion. The KruskalWallis one way analysis of variance was used to compare independent groups. The McNemar test was used to test the equality of response rates in paired dependent data. The $\chi^{2}$ statistic was applied to independent data tabulated in $2 \times 2$ or $2 \times k$ contingency tables. The relation between repeated measures of $\mathrm{FSBP} \% 10^{\circ}$ and several individual and exposure variables was assessed by the generalised estimating equations method for longitudinal data in order to account for the within subject correlation. ${ }^{16}$

\section{RESULTS}

The group of 73 VWF claimants, who were unsuccessful at the first examination, included construction workers $(n=10)$, caulkers $(n=11)$, grinders $(n=30)$, welders $(n=9)$, and mechanics $(n=13)$. These worker groups were comparable for age, anthropometric characteristics, and smoking and drinking habits (table 1). No worker received medical treatment for vascular disorders or diseases. Daily vibration exposure (hours) was greater in the caulkers 
Table 1 Characteristics of the study population at the first examination

\begin{tabular}{|c|c|c|c|c|c|}
\hline & $\begin{array}{l}\text { Construction } \\
\text { workers } \\
(\mathrm{n}=10)\end{array}$ & $\begin{array}{l}\text { Caulkers } \\
(n=11)\end{array}$ & $\begin{array}{l}\text { Grinders } \\
(\mathrm{n}=30)\end{array}$ & $\begin{array}{l}\text { Welders } \\
(n=9)\end{array}$ & $\begin{array}{l}\text { Mechanics } \\
(n=13)\end{array}$ \\
\hline Age (y) & $53(46-54)$ & $49(45-52)$ & $48(43-52)$ & $50(44-52)$ & $46(44-53)$ \\
\hline BMI $\left(\mathrm{kg} / \mathrm{m}^{2}\right)$ & $26(24-30)$ & $27(24-29)$ & $26(24-28)$ & $25(24-26)$ & $27(24-28)$ \\
\hline Smokers & $1(10.0)$ & $6(54.6)$ & $16(53.3)$ & $3(33.3)$ & $5(38.5)$ \\
\hline Drinkers & $7(70.0)$ & $6(54.6)$ & $20(66.6)$ & $4(44.4)$ & $9(69.2)$ \\
\hline \multicolumn{6}{|l|}{ Exposure } \\
\hline h/day & $2(1-3)$ & $4(3-5)$ & $2.5(2-5)$ & $2(1-3)$ & $2(1-3)^{\star \star}$ \\
\hline days/y & $100(80-200)$ & $200(150-220)$ & $200(150-220)$ & $150(100-180)$ & $200(150-220)^{*}$ \\
\hline years & $20(4-30)$ & $20(16-24)$ & $21(16-29)$ & $34(30-36)$ & $23(15-30)^{*}$ \\
\hline \multicolumn{6}{|l|}{ WWF symptoms } \\
\hline Stage 1 & $1(10.0)$ & $2(18.2)$ & $3(10.0)$ & $0(0)$ & $2(15.4)$ \\
\hline Stage 2 & $0(0)$ & $2(18.2)$ & 5 (16.7) & $0(0)$ & $4(30.8)$ \\
\hline Stage 3 & $0(0)$ & $2(18.2)$ & 7 (23.3) & $1(11.1)$ & $0(0)$ \\
\hline Stage $1+2+3$ & $1(10.0)$ & $6(54.6)$ & $15(50.0)$ & $1(11.1)$ & $6(46.2) \dagger$ \\
\hline $\begin{array}{l}\text { Sensorineural } \\
\text { symptoms }\end{array}$ & $10(100)$ & $11(100)$ & $27(90.0)$ & $9(100)$ & $13(100)$ \\
\hline \multicolumn{6}{|c|}{$\begin{array}{l}\text { WWF symptoms are staged according to a modified Stockholm scale (see methods). Values are given as medians } \\
\text { (quartiles) or numbers (\%). } \\
\text { BMI, body mass index. } \\
\text { Kruskal-Wallis test: }{ }^{*} p<0.05,{ }^{* *} p=0.025 ; \chi^{2} \text { test: } \dagger p<0.05\end{array}$} \\
\hline
\end{tabular}

$(p=0.025)$ and total duration of usage of vibrating tools (years) was greater in the welder group $(\mathrm{p}<0.05)$.

Almost all workers $(\mathrm{n}=70)$ reported sensorineural disturbances (tingling and/or numbness) in their fingers and hands. Three workers complained of cold fingers without episodes of blanching attack.

At the first examination, 29 vibration exposed workers had a positive history of VWF symptoms but normal cold test results. VWF symptoms were more frequent in caulkers, grinders, and mechanics when compared with construction workers and welders $(\mathrm{p}<0.05)$. Mean latency time for VWF was 7.0 (range 1-35) years. There was no association between VWF symptoms and drinking or smoking habits.

Of the 29 workers who claimed for VWF symptoms at the first examination, 26 reported unchanged digital vascular complaints, and three recovered from white finger during the follow up (table 2). The three workers who recovered from finger blanching had been classified as VWF stage $l(n=2)$ and stage $2(\mathrm{n}=1)$.

Over the follow up period, there were 14 new cases who reported white finger symptoms $(p<0.05)$ : eight new cases were classified as VWF stage 1 , four as VWF stage 2, and two as VWF stage 3. Among the new cases with VWF symptoms, four were construction workers, four welders, three grinders, two mechanics, and one caulker. Ten new cases reported VWF symptoms at the second examination and four at the third examination. In these subjects, the latency time for the appearance of VWF symptoms since the first examination averaged 3.4 (SD 1.8) years.

Significant deterioration in the distribution of VWF stages and the number of phalanges affected with whiteness was observed over the follow up period $(p<0.05)$. However, four workers showed an amelioration of VWF stage: one subject improved from stage 2 to stage 1 , and three men changed from stage 3 to stage 2 .

At the end of the follow up, 40 of 73 workers (54.8\%) had a positive history of VWF symptoms, three subjects had recovered from VWF, and 30 men complained of either peripheral sensorineural disturbances or cold fingers and hands without episodes of finger whiteness.

During the follow up period, cold response of the digital arteries deteriorated in eight workers (all among the incident cases of VWF): six cases showed the closing phenomenon of the digital arteries (zero FSBP at $10^{\circ} \mathrm{C}$ ) and two cases revealed an abnormal cold response of the digital arteries $\left(\mathrm{FSBP} \%_{10} 0^{\circ}<60 \%\right)^{2}$.

Six workers with digital arterial hyperresponsiveness to cold but no VWF symptoms at the first examination, reported a positive history of white finger at the second examination and showed persistent abnormal cold test results $\left(\mathrm{FSBP}_{10} \mathrm{O}^{\circ}<60 \%\right)^{\circ}$.

Eight workers with sensorineural disturbances in the fingers and hands and with increased vasoconstrictor response to cold in the digital arteries at the first examination, continued to show an abnormal pattern of cold response without development of white finger symptoms during the follow up.

Improvement in the cold test $\left(\mathrm{FSBP}_{10^{\circ}}>60 \%\right)$ was observed in six subjects (three with recovery from VWF, and three with amelioration of VWF stage).

At the end of the follow up period, 14 workers obtained compensation by the National Insurance Institute since they fulfilled the established compensatory criteria: a positive history of VWF symptoms and abnormal cold test results.

Table 2 Change in VWF symptoms from the first to the last examination in the vibration exposed workers

\begin{tabular}{llllll}
\hline & No vasospastic & \multicolumn{3}{l}{ Change in vascular disorders } \\
\cline { 3 - 5 } & symptoms/signs & Improved & Stationary & Deteriorated \\
\hline WWF symptoms & 30 & 3 & 26 & $14^{*}$ \\
Stage of VWF symptoms & 30 & 7 & 20 & $16^{*}$ \\
Number of phalanges with VWF symptoms & 30 & 6 & 16 & $21^{*}$ \\
Abnormal cold response (FSBP\% $\left.10^{\circ}<60 \%\right)$ & 45 & 6 & 14 & 8 \\
\hline Values are given as numbers. & & & & \\
McNemar test: * $\mathrm{p}<0.05$. & & & & \\
\hline
\end{tabular}


Table 3 Logistic regression of VWF symptoms and finger systolic blood pressure during local cooling to $10^{\circ} \mathrm{C}\left(\mathrm{FSBP} \% 10^{\circ}\right)$ on individual and exposure variables in the vibration exposed workers $(n=73)$

\begin{tabular}{llll}
\hline Predictors & $\begin{array}{l}\text { VWF symptoms } \\
\text { OR }(95 \% \mathrm{CI})\end{array}$ & $\begin{array}{l}\text { FSBP\% } 10^{\circ}<60 \% \\
\text { OR }(95 \% \mathrm{CI})\end{array}$ & $\begin{array}{l}\text { Zero FSBP\% } \\
\text { OR }(95 \% \mathrm{Cl})^{\circ}\end{array}$ \\
\hline Age (y) & $0.97(0.92$ to 1.03$)$ & $0.95(0.89$ to 1.01$)$ & $1.04(0.95$ to 1.12$)$ \\
Smoking (pack-y) & $1.01(0.99$ to 1.03$)$ & $1.00(0.97$ to 1.02$)$ & $0.97(0.94$ to 1.01$)$ \\
Daily vibration exposure (h) & $1.19(1.01$ to 1.41$)$ & $1.06(0.86$ to 1.30$)$ & $0.99(0.74$ to 1.31$)$ \\
Follow up time $(y)$ & $1.07(0.97$ to 1.19$)$ & $1.15(1.01$ to 1.32$)$ & $0.98(0.80$ to 1.20$)$ \\
WWF symptoms (0=no/1 =yes) & - & $4.24(1.93$ to 9.31$)$ & $6.57(1.95$ to 22.1) \\
\hline
\end{tabular}

$\mathrm{FSBP} \% 10^{\circ}$ is dichotomised at either $60 \%$ of the pressure at $30^{\circ} \mathrm{C}$ or at zero value (closure of the digital arteries). The generalised estimating equations (GEE) method was used to account for correlation between repeated measures of both dependent and independent variables within subject during the follow up period. Odds ratios (OR) and robust $95 \%$ confidence intervals $(95 \% \mathrm{Cl})$ are shown.

Analysis of repeated measures of FSBP during local cooling by the generalised estimating equations (GEE) method for longitudinal data showed that both abnormal cold response of digital arteries $\left(\mathrm{FSBP} \% 10^{\circ}<60 \%\right)$ and closure of the digital arteries (zero FSBP at $10^{\circ} \mathrm{C}$ ) were significantly associated with the presence of VWF symptoms (table 3). Moreover, exaggerated vasoconstrictor response to cold was related to the duration of vibration exposure since the first examination (that is, follow up time), whereas VWF symptoms were associated with daily exposure time during the follow up.

Marginal linear regression (GEE method) of $\mathrm{FSBP} \%_{10} 0^{\circ}$ on individual and exposure variables showed that the reduction of $\mathrm{FSBP} \% 10^{\circ}$ (that is, deterioration) was significantly related to the follow up time in both the incident cases of VWF $(-4 \%$ per year) and the workers with no symptoms of finger whiteness $(-3 \%$ per year) (table 4$)$. FSBP $\%_{10}{ }^{\circ}$ at the first examination and changes in $\mathrm{FSBP} \%_{10} 0^{\circ}$ during the follow up were not associated with either age or smoking habit.

\section{DISCUSSION}

VWF is a peripheral vascular disorder of occupational origin which is compensated in many industrialised countries. In a recent recommendation for a European schedule of occupational diseases, the Commission of the European Communities includes "angioneurotic diseases caused by mechanical vibration" (Annex I, item 505.02) among health disorders which show a direct link with occupation on the basis of clinical and epidemiological evidence. ${ }^{17}$ "Osteoarticular diseases of the hands and wrists caused by mechanical vibration" are also included in the new Commission recommendation (Annex I, item 505.01). In Italy, both VWF and bone and joint disorders of the upper limb are included in the official schedule of occupational diseases in industry (item 52) and agriculture (item 27). Moreover, pre-employment and yearly follow up health surveillance is prescribed for workers occupationally exposed to hand transmitted vibration. At present, vibration induced upper limb disorders represent the fifth occupational disease compensated in Italy. To obtain compensation, workers complaining VWF symptoms must undergo a series of clinical and laboratory examinations to assess objectively the presence of vascular disorders and their severity.

The results of this follow up study of VWF in active vibration exposed workers claiming for compensation are consistent with the findings of other investigations which suggest that continued work with hand held vibrating tools is significantly associated with an increase in the occurrence of VWF, increased severity of digital vasospastic symptoms, and increased responsiveness of digital arteries to cold. In a cohort study of welders exposed to hand transmitted vibration, Östman and colleagues ${ }^{7}$ found that among workers with continued vibration exposure, none showed subjective improvement, 56\% claimed unchanged problems, and $44 \%$ reported worse symptoms. In a follow up clinical study of 353 Japanese workers receiving treatment for hand-arm vibration syndrome, it was observed that continued use of vibratory tools was associated with an unfavourable prognosis for VWF. ${ }^{6}$ In a follow up study of the course of VWF in 55 Swedish men, patients who had continued to work with vibratory tools reported an increase in subjective symptoms which were associated with an increased vasoconstrictor response of the digital arteries to a standardised cold test. ${ }^{8}$ In a group of active stoneworkers using percussive and rotary tools, a $38 \%$ onset of new cases of VWF was observed in a six year follow up period. ${ }^{5}$ In a follow up clinical investigation of 102 patients with advanced stages of VWF, Petersen and colleagues $^{10}$ reported that continued exposure to hand transmitted vibration had a negative influence on VWF reversibility.

It is worth noting that most of the aforementioned studies pointed out that cessation or reduction of vibration exposure were associated with either recovery from VWF or

Table 4 Linear regression of $\mathrm{FSBP} \% 10^{\circ}$ on individual and exposure variables in the vibration exposed workers according to their subjective WWF status during follow up

\begin{tabular}{llll}
\hline & \multicolumn{3}{l}{ FSBP\% $1^{\circ}$ during follow up } \\
\cline { 2 - 4 } & $\begin{array}{l}\text { Never VWF symptoms } \\
(\mathbf{n}=30)\end{array}$ & $\begin{array}{l}\text { Incident cases of VWF } \\
\text { symptoms } \\
(\mathbf{n}=14)\end{array}$ & $\begin{array}{l}\text { Prevalent cases of VWF } \\
\text { symptoms } \\
(\mathbf{n}=\mathbf{2 6})\end{array}$ \\
Predictors & $135(30.0)$ & $14.0(38.5)$ & $70.9(32.1)$ \\
\hline Intercept & $-0.78(0.59)$ & $0.11(0.67)$ & $0.41(0.79)$ \\
Age (y) & $-0.31(0.18)$ & $-0.09(0.22)$ & $0.49(0.26)$ \\
Smoking (pack-y) & $-1.92(1.58)$ & $-2.00(3.43)$ & $-1.97(2.55)$ \\
Daily vibration exposure (h) & $-2.86(1.01)^{* *}$ & $-4.14(1.82)^{*}$ & $0.04(1.78)$ \\
Follow up time (y) & &
\end{tabular}

Estimates of regression coefficients (robust standard errors) by the GEE method are shown. †Three subjects, who had recovered from VWF, were excluded from analysis. ${ }^{*} \mathrm{p}=0.02 ;{ }^{* *} \mathrm{p}<0.01$. 
improvement of VWF stages. In some studies of forestry workers, the decrease in the incidence of VWF in active chain sawyers was attributed to the use of lighter anti-vibration (AV) chain saws and the introduction of administrative measures curtailing daily saw usage time and improving the organisation of forest work. ${ }^{23}$ It should be noted, however, that new cases of VWF have been reported in active workers who used AV tools of new generation. ${ }^{1}{ }^{118}$ These findings suggest that health surveillance should be maintained in workers whose work experience is limited to AV tools only. This is also consistent with the provisions established by the new European Directive 2002/44/EC on the protection of workers against risks arising from mechanical vibration. ${ }^{19}$

In this study, an abnormal response of digital arteries to cold provocation was associated with both VWF symptoms and the duration of vibration exposure since the first examination. As expected, digital arterial hyperresponsiveness to cold was significantly related to the follow up time in the incident cases of VWF. However, a significant reduction of $\mathrm{FSBP} \%_{10^{\circ}}$ (that is, aggravation) was also observed in workers with no episodes of finger blanching attacks during the follow up period. Similar findings have been reported by other researchers who investigated prospectively the changes in the occurrence of VWF by means of medical interview and cold test. ${ }^{1820}$ A deterioration of FSBP\% during cooling was observed in asymptomatic workers who had operated only $\mathrm{AV}$ tools. This means that damage to the vasoconstrictor mechanisms in the digital arteries may occur even in subjects exposed to hand transmitted vibration of low intensity.

It is believed that a medical interview carried out by a qualified physician is the currently best available method to perform an anamnestic diagnosis of VWF. ${ }^{1121}$ It is also thought that a positive cold test is essential to make a definite diagnosis of VWF. ${ }^{21}$ In this study, there was a discrepancy between medical interview outcome and the results of objective testing: at the end of the follow up period, 55\% of the VWF claimants reported white finger symptoms at the medical interview, while only $19 \%$ had a positive history of VWF combined with abnormal cold test results (FSBP\% $<60 \%$ ). This finding is very similar to that reported by Allen et al who investigated cross-sectionally 79 claimants for VWF compensation. ${ }^{22}$ In this group of claimants, $83.5 \%$ reported white finger symptoms, but only 19\% showed abnormal vasoconstrictor response to a cold test conducted with a method which was only slightly different from that adopted in our study. In agreement with the opinion of the aforementioned researchers, one reason for the discrepancy between subjective and objective findings may be the medicolegal context in which the studies were performed. In a litigation situation, either over-reporting or overestimation of symptoms by claimants, especially those symptoms known to be linked to a prescribed occupational disease, cannot be ruled out. In such a context, questionnaire or medical interview methods may fail to identify VWF claimants with a true history of finger blanching attacks. Alternatively, it can be hypothesised that the cold testing method used in this study has insufficient sensitivity to minimise false negative cold test results in subjects with a true history of VWF symptoms. The diagnostic accuracy of cold provocation test measuring FSBP has been investigated in some cross-sectional studies, including large samples of vibration exposed workers with and without VWF symptoms. ${ }^{21}{ }^{23}{ }^{24}$ Assuming an FSBP\% $10^{\circ}<60 \%$ as the cut-off value between normal and abnormal response of the digital arteries to cooling, the sensitivity of the cold test to detect VWF was found to range between $74 \%$ and $99 \%$, while the specificity varied from $94 \%$ to $99 \%$. The positive predictive value of the cold test was strongly dependent on the prevalence of VWF in the investigated worker groups and ranged between $75 \%$ and
99\%. Differences in the cooling procedures and the prevalence and severity of VWF symptoms may explain the differences in the diagnostic accuracy of the cold test in the various cross-sectional studies. These findings suggest that FSBP measurement after finger cooling is a sufficiently accurate laboratory testing method to detect cold induced digital vasospasm and to confirm VWF symptoms objectively in vibration exposed workers with a reliable history of white finger.

Nevertheless, prospective studies have pointed out either concordance or discrepancy between the course of VWF symptoms and the course of cold provocation outcomes. Some follow up studies have observed that a reduction in or cessation of exposure to hand transmitted vibration had a beneficial effect on both finger blanching symptoms and the cold response of digital arteries. ${ }^{118}$ Other follow up studies of vibration exposed workers have reported that subjective improvement in symptoms was not confirmed at the cold provocation, and vice versa improvement in the cold response was not reflected in improvement in subjective experience of finger blanching attacks. ${ }^{8}{ }^{10} 25$ These findings suggest that the cold test with measurement of FSBP may have limitations as a laboratory tool for the prognosis of VWF. These limitations may be attributed to some aspects of study design because most of the currently available prospective studies include either high risk worker groups or VWF claimants. On the other hand, the poor prognostic performance of the cold test reported in some follow up studies may reflect our incomplete knowledge of the pathophysiological mechanisms underlying the adverse effect of hand transmitted vibration on finger circulation.

As mentioned above, in our study the cold test could reveal an increased hyperreactivity to cold provocation in vibration exposed workers with a negative anamnesis for finger blanching attacks. Eight subjects without VWF symptoms exhibited an abnormal digital arterial response to cold, suggesting that FSBP measurement during local cooling may be useful to uncover subjects with exaggerated vasoconstrictor mechanisms, for whom a strict periodic medical surveillance should be implemented. We recognised that it may be questionable to draw firm conclusions from the results of a follow up study of the course of VWF in a highly selected group of VWF claimants. However, our finding that six workers with no vascular symptoms but with exaggerated cold response at the first examination developed VWF during the follow up, tends to support, at least partially, the hypothesis that an abnormal cold test may be a prodromal sign of possible development of white finger at a later time.

In this study, there were no significant associations between VWF symptoms and smoking, and between the results of the cold test and smoking both at the first examination and during the follow up. The role of tobacco consumption on the course of VWF is still a controversial matter. The findings of some clinical and epidemiological studies suggest that smokers have a poorer prognosis for VWF. ${ }^{1025}$ It has been reported that after cessation or reduction of vibration exposure, the rate of VWF recovery was greater and the improvement in the cold response of digital vessels was more evident in non-smokers or exsmokers than in current smokers. On the contrary, other studies have reported no influence of smoking on either the progression of VWF in current users of vibratory tools or the reversibility of VWF in ex-users. ${ }^{1626}$ Even though the adverse effects of smoking on arterial function are well known, nevertheless its contribution to the onset and development of VWF symptoms, as well as its influence on VWF reversibility, are not yet established. 


\section{Conclusion}

This follow up study showed that 14 new cases of VWF occurred in a selected group of currently active vibration exposed workers who claimed for VWF compensation. In the entire sample of VWF claimants, there was a discrepancy between positive history of VWF symptoms at the medical interview (55\%) and abnormal cold test results (19\%). This finding suggests that medical interview outcomes should be interpreted with caution in medicolegal situations involving VWF claimants. Over the follow up period, the cold response of digital arteries deteriorated significantly not only in the incident cases of VWF but also in the vibration exposed workers with no digital vasospastic symptoms during the follow up. In the incident cases of VWF, finger blanching attacks became visible after about 3.5 years since the first examination. This finding suggests that impairment to digital vasculature can develop over a short time in workers with current exposure to hand transmitted vibration from power tools. That a few extra years of continued work with vibratory tools have caused a significant increase in the occurrence of VWF symptoms and signs among currently active men employed in various industrial sectors, is a matter of concern for the occupational health physician. This argues for the adoption and implementation of preventive measures to improve the safety and health of vibration exposed operators at work as required by the European Directive on mechanical vibration. ${ }^{19}$

\section{ACKNOWLEDGEMENTS}

This research was supported by the European Commission under the Quality of Life and Management of Living Resources programmeProject No. QLK4-2002-02650 (VIBRISKS).

\section{Authors' affiliations}

M Bovenzi, A Della Vedova, C Negro, Clinical Unit of Occupational Medicine, Department of Public Health Sciences, University of Trieste, Trieste 34129, Italy

Competing interests: none declared

\section{REFERENCES}

1 Bovenzi M, Alessandrini B, Mancini R, et al. A prospective study of the cold response of digital vessels in forestry workers exposed to saw vibration. Int Arch Occup Environ Health 1998;71:493-8.

2 Futatsuka M, Ueno T, Sakurai T. Cohort study of vibration-induced white finger among Japanese forest workers over 30 years. Int Arch Occup Environ Health 1989;61:503-6.

3 Koskimies K, Pyykkö I, Starck J, et al. Vibration syndrome among Finnish forest workers between 1972 and 1990. Int Arch Occup Environ Health 1992;64:251-6.

4 Riddle HFV, Taylor W. Vibration-induced white finger among chain sawyers nine years after the introduction of anti-vibration measures. In: Brammer AJ, Taylor W, eds. Vibration effects on the hand and arm in industry. New York: John Wiley \& Sons, 1982:169-72.
5 Bovenzi M, Franzinelli A, Scattoni L, et al. Hand-arm vibration syndrome among travertine workers: a follow up study. Occup Environ Med 1994;51:361-5.

6 Ogasawara C, Sakakibara H. Longitudinal study on factors related to the course of vibration-induced white finger. Int Arch Occup Environ Health 1997;69:180-4.

7 Östman F, Lundborg G, Bornmyr S, et al. Is vibration-induced white finger a reversible syndrome if vibration is stopped? J Hand Surg 1996;21B:750-2.

8 Ekenvall L, Carlsson A. Vibration white finger: a follow up study. $\mathrm{Br} J$ Ind Med 1987;44:476-8.

9 Kurosawa Y, Nasu Y, Hosoda T, et al. Long-term follow-up study on patients with vibration-induced white finger (VWF). J Occup Environ Med 2002;44:1203-6.

10 Petersen R, Andersen M, Mikkelsen S, et al. Prognosis of vibration induced white finger: a follow up study. Occup Environ Med 1995;52:110-15.

11 Olsen N, Hagberg M, Ekenvall L, et al. Clinical and laboratory diagnostics of vascular symptoms induced by hand-arm vibration. Report from discussion in a working group. In: Gemne G, Brammer AJ, Hagberg M, et al, eds. Proceedings of the Stockholm Workshop 94, Hand-arm vibration syndrome:diagnostics and quantitative relationships to exposure. Arb Hälsa 1995;5:181-6.

12 Gemne G, Pyykkö I, Taylor W, et al. The Stockholm Workshop scale for the classification of cold-induced Raynaud's phenomenon in the hand-arm vibration syndrome (revision of the Taylor-Pelmear scale). Scand J Work Environ Health 1987; 13:275-8.

13 Nielsen SL, Lassen NA. Measurement of digital blood pressure after local cooling. J Appl Physiol 1977;43:907-10.

14 International Organisation for Standardisation. Mechanical vibration and shock-Cold provocation tests for the assessment of peripheral vascular function-Part 2: measurement and evaluation of finger systolic blood pressure. ISO/DIS 14835-2, 2004(E).

15 Bovenzi M. Vibration-induced white finger and cold response of digital arterial vessels in occupational groups with various patterns of exposure to hand-transmitted vibration. Scand J Work Environ Health 1998;24:138-44.

16 Diggle PJ, Liang KY, Zeger SL. Analysis of longitudinal data. Oxford: Oxford University Press, 1994.

17 Commission Recommendation of 19 September 2003 concerning the European schedule of occupational diseases (2003/670/EC). Official Journal of the European Union, L238/28, 25.9.2003.

18 Olsen N, Nielsen SL. Vasoconstrictor response to cold in forestry workers: a prospective study. Br J Ind Med 1988;45:39-42.

19 Directive 2002/44/EC of the European Parliament and the Council of 25 June 2002 on the minimum health and safety requirements regarding the exposure of workers to the risks arising from physical agents (vibration) (sixteenth individual Directive within the meaning of Article 16(1) of Directive 89/391/ EEC). Official Journal of the European Communities, L1 17/13, 6.7.2002.

20 Olsen N, Nielsen SL, Voss P. Cold response of digital arteries in chain saw operators. Br J Ind Med 1982;39:82-8.

21 Olsen N. Finger systolic blood pressure during cooling in VWF; value of different diagnostic categories for a routine test method. In: Lundström R, Lindmark A, eds. Proceedings of the 8th International Conference on HandArm Vibration. National Institute for Working Life. Arbetslivsrapport 2000;4:65-9.

22 Allen JA, McGrann S, McKenna KM. Use of questionnaire screening for vibration white finger in a high risk industrial population. Int Arch Occup Environ Health 2002;75:37-42.

23 Ekenvall L, Lindblad LE. Vibration white finger and digital systolic pressure during coolin. Br J Ind Med 1986;43:280-3

24 Bovenzi M. Finger systolic blood pressure indices for the diagnosis of vibration-induced white finger. Int Arch Occup Environ Health 2002;75:20-8.

25 Cherniack M, Clive J, Seidner A. Vibration exposure, smoking, and vascular dysfunction. Occup Environ Med 2000;57:341-7.

26 Futatsuka M, Sakurai T. A case-control study on the prognosis of vibration syndrome. Int Arch Occup Environ Health 1986;58:113-20. 